\title{
The influence of the nonwoven veil architectures on interlaminar fracture toughness of interleaved composites
}

\author{
Victor A. Ramirez ${ }^{\mathrm{a}}$, Paul J. Hogg ${ }^{\mathrm{b}}$ and William W. Sampson ${ }^{\mathrm{a}, \dagger}$

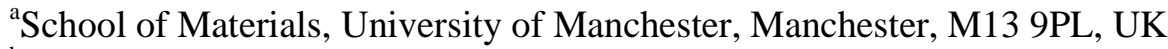 \\ ${ }^{\mathrm{b}}$ Royal Holloway, University of London, Surrey, TW20 0EX, UK \\ ${ }^{\dagger}$ Corresponding author: sampson@manchester.ac.uk; +44-(0)161-306-3898
}

\begin{abstract}
Nonwoven veils with a range of weights formed from polyphenylenesulfide (PPS) fibres with different diameter were interleaved within unidirectional carbon fibre epoxy composites and their mode I and mode II interlaminar fracture toughness (IFT) measured. In modes I and II the IFT increases with the areal density of the veil up to a plateau; at a given areal density, the mode I IFT is greater for thin fibres than for thicker fibres. For the PPS veils, we observe no significant influence of nonwoven anisotropy on IFT; though some dependence is observed for a highly anisotropic PEEK veil. Interpretation of the results using theory describing nonwoven architectures reveals that for both modes the IFT depends on the mean coverage of the veil and hence on the fraction of the propagating crack front that contains no fibres. Results for composites formed from a veil of polyetheretherketone (PEEK) fibres exhibit behaviours consistent with those observed for PPS.
\end{abstract}

KEYWORDS: Layered structures (A); Polymer matrix composites (A); Fracture toughness (B); Nonwovens.

\section{Introduction}

Laminated fibre reinforced composites are used increasingly for structural applications in the automotive, energy [1] and aerospace [2-5] sectors. They are light-weight, relatively easy to manufacture and exhibit good performance under loading and at high temperature. More widespread application has been limited by the propensity for interlaminar failure of the composite under mode I and mode II loading. Insufficient resistance to interlaminar stresses through fibre-polymer interactions results in the generation of cracks [6, 7]; above some critical stress, characterised by the critical interlaminar fracture toughness, these cracks will propagate resulting in delamination. Accordingly, interlaminar fracture toughness is a key parameter to assess the performance of composites under conditions such as fatigue [8, 9], compression [10], impact [11-13] or compression after impact [14-17]; in each of these cases, delaminations due to mode I and II loading are a principle cause of material failure [9, 17-20]. 
Now, cracks and imperfections resulting in delamination may arise from local variability in materials properties, voids or other imperfections occurring during manufacturing, or through damage sustained in-service. Regardless of the nature of flaws, it is inevitable that those located at the surface of the material will be more readily identified, e.g. by simple inspection, than those located inside the composite; here more advanced analytic techniques must be applied [21]. Interlaminar fracture toughness testing protocols and standards [22, 23] offer an approach to assess the energy required for crack initiation and eventual propagation by measuring delamination length in samples under mode I or mode II loading to obtain the fracture energy release rates, $G_{I c}$ or $G_{I I c}$, respectively.

Strategies to improve the interlaminar fracture toughness in composites include modifying fabric architectures [24-29] by manufacturing, e.g. 2D patterns [28, 29], weft-knitted fabrics [26] or 3D textiles [29, 30]. In each case the volume fraction of fibres in the composite and its homogeneity is key; the absorption of stresses induced during loading being improved for a greater and more homogenous fibre fraction. However, such approaches do bring complexity to manufacturing processes, and can result in poor resin infusion, generating voids and wrinkles, which may eventually lead to micro cracks [31]. These are found also when elements are inserted out-of-plane e.g. Z pins or stitching tows. Thus, although such techniques may considerably improve interlaminar fracture toughness in both modes [32, 33], the increased propensity for discontinuities can compromise their in-service performance [20].

Interleaved composite systems, where layers of high-toughness resin are introduced within composites, have been applied with CFRP prepregs; these increase interlaminar fracture toughness in both modes I and II [34], but increase also composite thickness and weight [9, 35]. Gillespie [7, 36] and Smiley \& Pipes [37] demonstrated that the fracture behaviour of 
interleaved composites is characterized by the radius of the plastic deformation zone at the propagating crack front. This radius depends on the mechanical properties of the interlayer and the opening rate; when the radius is greater than the interlayer thickness the plastic area extends beyond its boundaries and cracks appear in the bonded interfaces between interlayer and fibres, rather than those between fibres and matrix, which are typically stronger. Although advances in resin toughening technology have improved the interlaminar fracture toughness of interleaved composites, Kuwata and Hogg [16] consider that these gains are approaching the limit of what may be achieved. Following Lee and Noguchi [38-40], they considered instead the use of nonwoven textile veils for interleaving CFRP composites and found significant improvements in mode I and mode II fracture toughness when using polymer veils.

Nonwoven textiles consist of a web of stochastically distributed fibres bonded to each other. The fibres used and the mass per unit area, or 'areal density' of the web depend on end-use application; these include gas filters, fluid absorbers, surfaces corrosion protectors, etc. [41, 42]. Preliminary studies of hybrid composites using nonwovens show some improvement in delamination resistance accompanied by a reduction in tensile strength and shear modulus [38]. Subsequently, the improved mode II interlaminar fracture toughness was found to depend on the location of crack tip propagation such that the mode II fracture toughness, $G_{I I c}$, was greatest when crack propagation is close to the mid-plane [40]; improvements in mode I fracture toughness were limited however [39]. Subsequently, Kuwata and Hogg [31, 43] examined the properties of interleaved composites formed from different veils. They showed that for mode I, veils with low areal density and with thermoplastic fibres seemed to be the most effective for absorbing fracture energy. For mode II the fracture energy was seemingly dependent on the interleaved nonwoven architecture. 
Nonwoven textiles used in composites are usually wet-laid, i.e. they are formed by continuous filtration of a dilute fibrous suspension in water. The resultant nonwoven mat typically exhibits a preferential orientation of fibres in the direction of manufacture (MD) and accordingly exhibits a corresponding mechanical anisotropy such that tensile strength and modulus in the MD are greater than those in the perpendicular, or cross-direction (CD) [42].

Nonwoven textiles are characterised by their heterogeneous, stochastic structures. Frequently these are modelled as random fibre networks where the location of each fibre is independent of those of all other fibres and the distribution of fibre orientation to any given direction is uniform. There is a considerable literature describing the structure of these random fibre networks, see, e.g. [44], and statistical models of these structures have been widely applied to the characterisation of paper, fibrous filter media [45, 46] and, more recently, electrospun polymer fibre networks [47] . Typically, such models seek to give structural properties of the network in terms of network properties such as porosity and areal density, and fibre properties such as length, width and linear density; note that the linear density of a fibre is given by the product of the cross-sectional area and density, irrespective of the cross sectional shape, so for fibres with circular cross-section, with diameter, $\omega(\mathrm{m})$, formed from a polymer of density, $\rho$ $\left(\mathrm{kg} \mathrm{m}^{-3}\right)$, the linear density, $\delta\left(\mathrm{kg} \mathrm{m}^{-1}\right)$, is given by

$$
\delta=\frac{\pi \omega^{2} \rho}{4}
$$

The specific surface area, $S_{f}\left(\mathrm{~m}^{2} \mathrm{~kg}^{-1}\right)$ of fibres with circular cross-section is

$$
S_{f}=\frac{\pi \omega}{\delta}=\frac{4}{\rho \omega} .
$$

The number of fibres covering a point in the plane of support of the network is a discrete random variable called coverage, $c$, and classical statistical models for network structure 
assume that the distribution of coverage at points is given by the Poisson distribution such that in a network with mean coverage, $\bar{c}$, the probability that a point in the network has coverage, $c$ is given by

$$
P(c)=\frac{\bar{c}^{c} e^{-\bar{c}}}{c !} \quad \text { for } c=0,1,2,3 \ldots
$$

The mean coverage is given by the ratio of the mean areal density of the network, $\bar{\beta}\left(\mathrm{kg} \mathrm{m}^{-2}\right)$ to that of the constituent fibres, $\beta_{f}\left(\mathrm{~kg} \mathrm{~m}^{-2}\right)$. Intuitively, the mass per unit area of fibres is given by the ratio of the linear density to the fibre width, so the mean coverage is given by

$$
\bar{c}=\frac{\bar{\beta}}{\beta_{f}}=\frac{\bar{\beta} \omega}{\delta} .
$$

For extensive discussion of the use of Poissonian statistics to yield structural statistics of fibrous architectures, see [44]. For now, we note two results arising from such considerations: the fraction of the network that is not covered by fibres, where resin can infuse directly from one side of the veil to the other is given by the Poisson probability of coverage zero, i.e.

$$
P(c=0)=e^{-\bar{c}} \text {. }
$$

In a network with porosity, $\varepsilon$, the expected dimension of inter-fibre voids differs in the plane $(x-y)$ and plane-perpendicular $(x-z)$ directions of the network such that [48].

$$
\bar{d}_{x y} \approx 2 \bar{d}_{x z}=\frac{2 \omega}{\log (1 / \varepsilon)}
$$

Eqns. (2) to (6) provide the dependencies that give rise to this study. From Eqn. (4) we observe that changing fibre dimensions allows the mean coverage to be varied independently of areal density; coupled with Eqn. (5) it follows that the fraction of pin-holes in a network with given areal density will depend on fibre dimensions also. Similarly, Eqns. (2) and (6) reveal that at a given porosity the mean pore size is directly proportional to the diameter of the constituent 
fibres, whereas the specific surface area of fibres is inversely proportional to their diameter. So, the structural characteristics of nonwoven veils that we expect to influence composites performance can be influenced by choice of fibres.

Here, we present an experimental study designed to investigate the interlaminar fracture toughness of interleaved composites manufactured from nonwoven veils with systematically varying structural characteristics. Interpretation of the resultant data is guided by the statistical theory of fibre and network properties as given by Eqns. (1) to (6).

\section{Materials}

Composites with a symmetrical construction of layers of unidirectional carbon fibre fabrics around a central layer of nonwoven polymer veil were prepared for testing. For all specimens, the resin used was Epoxy Araldite ${ }^{\circledR}$ LY 564 with Hardener XB 3486, from Huntsman Advanced Materials. Unidirectional carbon T300 fibre fabric, UD1 was supplied by FORMAX; it had areal density $340 \mathrm{~g} \mathrm{~m}^{-2}$ and thickness $260 \mu \mathrm{m}$. Unidirectional carbon T300 fibre fabric, UD2 was supplied by Sygmatex; it had areal density $300 \mathrm{~g} \mathrm{~m}^{-2}$ and thickness $300 \mu \mathrm{m}$.

Nonwoven veils were supplied by Technical Fibre Products Ltd., Cumbria, UK. One veil sample had nominal areal density $11 \mathrm{~g} \mathrm{~m}^{-2}$ and was formed from polyetheretherketone (PEEK) fibres with linear density 1.4 dtex $\left(1.4 \times 10^{-7} \mathrm{~kg} \mathrm{~m}^{-1}\right)$. Two sets of veils manufactured from polyphenylenesulfide (PPS) were provided: one set was made from fibres with linear density 1 dtex $\left(1 \times 10^{-7} \mathrm{~kg} \mathrm{~m}^{-1}\right)$ and the other from fibres with linear density 2 dtex $\left(2 \times 10^{-7} \mathrm{~kg} \mathrm{~m}^{-1}\right)$. Each set had a range of areal densities between $7 \mathrm{~g} \mathrm{~m}^{-2}$ and $35 \mathrm{~g} \mathrm{~m}^{-2}$. Accordingly, and guided by our discussion of Eqns. (2) to (6), we expect the PPS veils to exhibit a range of mean coverages, specific surfaces and mean pore size. 


\section{Sample preparation}

Composite panels were manufactured by resin infusion using layers of UD1 and UD2 carbon fibre fabrics and a layer of nonwoven veil as illustrated in Fig. 2. The nonwoven veil was cut shorter than the UD fabrics and a piece of $13 \mu \mathrm{m}$ release film was placed at each end of the veil. These layers were assembled in a steel mould with all layers of UD fabrics oriented parallel to the long direction of the sample; sample dimensions are shown in Fig. 2. Once the layout was prepared, the blend of resin and hardener (34\% w/w on resin) was degassed for approximately 50 minutes at $-1 \mathrm{~atm}$ and $20^{\circ} \mathrm{C}$ before being infused into the dry panel. The infused panel was cured by being raised to $80^{\circ} \mathrm{C}$ from room temperature over $1 \mathrm{hr}$; this temperature was then maintained for 8 hrs before cooling in ambient conditions [49]. Given the anisotropic nature of nonwoven veils, which arises from their directional manufacturing process [42], composites were prepared with the direction of manufacture of the veil (MD) oriented with the direction of the UD fibre and for some conditions an additional, otherwise identical, sample was prepared with the perpendicular or cross-direction (CD) oriented with the direction of the UD fibre.

\section{Characterization of veils}

The areal density of the nonwoven veils was determined gravimetrically and thickness was measured were using an electronic micrometer following international standards for characterising paper (ISO 5270:2012). For the PPS veils, tensile testing was carried out on $15 \mathrm{~mm}$ wide strips between jaws set $100 \mathrm{~mm}$ apart using an Instron 4411 universal testing machine; elastic modulus was measured at the steepest part of the load-elongation curve and 10 repeats were carried out in both $\mathrm{CD}$ and $\mathrm{MD}$.

Now, the inherent heterogeneity of nonwoven fibrous materials is such that most measures of thickness overestimate the true thickness and hence result in an underestimate of network density $[50,51]$. Conveniently, the specific elastic modulus, $E^{*}\left(\mathrm{~N} \mathrm{~m} \mathrm{~kg}^{-1}\right)$, usually calculated 


\begin{tabular}{|c|c|c|c|c|c|c|c|c|c|}
\hline & \multicolumn{4}{|c|}{ Fibre } & \multicolumn{5}{|c|}{ Veil } \\
\hline & \multirow{2}{*}{$\begin{array}{c}\text { Density, } \\
\rho \\
\left(\mathrm{g} / \mathrm{cm}^{3}\right)^{\mathrm{a}}\end{array}$} & \multirow{2}{*}{$\begin{array}{c}\text { Linear } \\
\text { density, } \\
\delta \text { (dtex) }\end{array}$} & \multirow[b]{2}{*}{$\begin{array}{c}\text { Diameter, } \\
\omega(\mathrm{mm})\end{array}$} & \multirow[b]{2}{*}{$\begin{array}{l}\text { Length, } \\
\lambda(\mathrm{mm})\end{array}$} & \multicolumn{3}{|c|}{ Regression data } & \multirow{2}{*}{$\begin{array}{c}\text { Density, } \\
\rho_{n \cdot} \\
\left(\mathrm{g} / \mathrm{cm}^{3}\right)\end{array}$} & \multirow[b]{2}{*}{$\begin{array}{c}\text { Porosity } \\
\varepsilon\end{array}$} \\
\hline & & & & & $\begin{array}{c}\text { Gradient } \\
\left(\mathrm{cm}^{3} / \mathrm{g}\right)\end{array}$ & $\begin{array}{l}\text { Intercept } \\
\text { (um) }\end{array}$ & $r^{2}$ & & \\
\hline \multirow{2}{*}{ PPS } & \multirow{2}{*}{1.30} & 1 & $10.0^{b}$ & 6 & 4.81 & 11.8 & 0.998 & 0.21 & 0.84 \\
\hline & & 2 & $14.0^{\mathrm{b}}$ & 6 & 4.95 & 15.1 & 0.991 & 0.20 & 0.85 \\
\hline PEEK & 1.32 & $1.4^{\mathrm{b}}$ & 11.5 & 12 & --- & --- & --- & $0.14^{\mathrm{C}}$ & $0.90^{\mathrm{C}}$ \\
\hline
\end{tabular}

Table 1 Characteristics of fibres and nonwovens. ${ }^{a}$ Data from [52]; ${ }^{b}$ computed using Eqn. (1); ${ }^{c}$ undersestimated value computed from areal density and thickness of one veil.

as the ratio of Young's modulus, $E_{y}\left(\mathrm{~N} \mathrm{~m}^{-2}\right)$ to network density, $\rho_{n}\left(\mathrm{~kg} \mathrm{~m}^{-3}\right)$ can be calculated without knowledge of network thickness from a plot of load per unit width, $F_{w}\left(\mathrm{~N} \mathrm{~m}^{-1}\right)$ against strain, $s$, and the areal density of the network, $\bar{\beta}\left(\mathrm{kg} \mathrm{m}^{-2}\right)$ :

$$
E^{*}=\frac{E_{y}}{\rho_{n}}=\frac{1}{\rho_{n}} \frac{\mathrm{d} \sigma}{\mathrm{d} s}=\frac{1}{\bar{\beta}} \frac{\mathrm{d} F_{\mathrm{w}}}{\mathrm{d} s}
$$

For the networks with a range of areal densities formed from PPS, we obtain the network density, $\rho_{n}$ as the reciprocal of the gradient of a plot of network thickness against areal density $[50,51]$. We illustrate this by example in Fig. 3 using our data for PPS nonwovens; fibre data and regression outputs are provided in Table 1. From Fig. 3 we observe good linear relationships between areal density and thickness with similar gradients, such that the densities of the two families of nonwoven veils can be considered similar and approximately $0.2 \mathrm{~g} \mathrm{~cm}^{-3}$. Note that computing the density directly from the ratio of areal density and thickness of individual samples would lead to the erroneous interpretation that density increased with areal density and was greater for the veils formed from thinner fibres. Both errors arise from the small positive intercepts on the ordinate in Fig. 3; we note that these are approximately equal to the corresponding fibre diameters given in Table 1. On this basis, we expect the density reported in Table 1 for PEEK fibres to be an underestimate; assuming the true thickness of the veil to be one fibre diameter less than measures yields an estimate of $0.16 \mathrm{~g} \mathrm{~m}^{-2}$. 
The mechanical testing of the veils revealed no significant difference in the specific elastic moduli of veils formed at different areal densities from a given fibre type when tested in a given direction; this is illustrated in Fig. 4 where the horizontal broken lines represent the mean value across all samples for a given set of data. We observe also that for the PPS veils the mechanical anisotropy in the networks formed from the 2 dtex fibres $\left(E_{\mathrm{MD}}: E_{\mathrm{CD}}=2.4: 1\right)$ was greater than that for those formed from the 1 dtex fibres (1.7:1); the greatest mechanical anisotropy was observed for the veil formed from PEEK fibres (4.0:1).

\section{Characterisation of composites}

The interlaminar fracture toughness of the composites was determined for modes I and II following established protocols. Mode I interlaminar fracture toughness was determined following ISO 15024:2001. Specimen dimensions were $25 \times 150 \mathrm{~mm}$ ( $c f$. Fig. 2); the test was performed using an Instron 5969 universal testing machine with a load cell of $10 \mathrm{kN}$ using a crosshead displacement speed of $3 \mathrm{~mm} \mathrm{~min}^{-1}$. The mode I energy release rate, $G_{I}$, was calculated using the Corrected Beam Theory method described in the standard and given by Eqn. (8).

$$
G_{I}=\frac{3 P x}{2 b(a+|\Delta|)},
$$

where $P$ is the applied load $(\mathrm{N}), x$ is the displacement $(\mathrm{m}), b$ is the width of the specimen $(\mathrm{m}), a$ is the delamination length $(\mathrm{m})$ and $\Delta$ is a correction factor (m) due to rotation of delamination front and obtained from a plot of $C^{1 / 3}$ against delamination length $a$ as the intercept of a linear regression with the abscissa when $C=0$; note that $C=x / P[22]$

Mode II fracture toughness was measured using an end-notched 4-point bending method [53]; the geometry of the bending fixture is shown in Fig. 5. Sample loading was carried out following the standard for mode I using a crosshead displacement speed of $1 \mathrm{~mm} \mathrm{~min}^{-1}$. The 
mode II fracture toughness, $\mathrm{G}_{\text {II }}$ was calculated using the compliance calibration method [53], as given by Eqn. (9).

$$
G_{I I}=\frac{P^{2} m}{2 b},
$$

where $m$ is the slope generated by a plot of compliance, $C$, against delamination length.

For each mode, the fracture toughness at initial delamination, $G_{I c}$ and $G_{I I c}$, and the fracture toughness for subsequent crack propagation, $G_{I p r o p}$ and $G_{I I p r o p}$, were determined; 7 repeats were carried out for each condition. Examples of load displacement curves and the resultant Rcurves are shown in Figs. 6 and 7 for composites formed with 1 dtex PPS veils oriented in the MD for modes I and II, respectively. In each case, in the interests of clarity, curves are shown for a subset of areal densities. The influence of veil weight on the loads applied and hence fracture toughness are apparent on first inspection. Inevitably, there is some variability within sample sets, so the curves shown in Figs. 6 and 7 have been selected as being representative of 'typical' behaviour. In our subsequent presentation of the data arising from repeated testing, error bars representing $95 \%$ confidence intervals on the data are included, Where the variability is sufficiently small, error bars are obscured by the data marker.

\section{Results and Discussion}

Results for mode I fracture toughness are shown in Figure 8; the plot on the left shows mode I fracture toughness plotted against the areal density of the veils; given the fixed density of all veils of approx. $0.2 \mathrm{~g} \mathrm{~cm}^{-3}$, the reported values of areal density can be converted to an approximate thickness value in microns by multiplying by 5 . We observe an increase in fracture toughness with increasing areal density. At low areal densities, there is little effect of veil type; at the higher areal densities tested the data suggest a plateau in the fracture toughness, and this is somewhat greater for the veils formed from fibres with low linear density than for 
fibres with high linear density. We do note that at the highest areal density tested the reverse is observed, though the variability in the measured fracture toughness is greater here. To a first approximation, there is no significant effect of veil orientation on the mode I fracture toughness for the PPS veils, though the fracture toughness is somewhat greater for the composites made from PEEK veils oriented in CD than those oriented in MD. Note that the mechanical anisotropy, and hence presumably the structural anisotropy, was markedly greater for the PEEK veils than for the PPS veils suggesting that network anisotropy needs to be considerable if it is to have a significant effect on composite properties. The plot on the right of Figure 8 shows the mode I fracture toughness during propagation, $G_{\text {Iprop }}$, is plotted against fracture toughness, $G_{\text {Ic }}$. Across the data set, we observe that $G_{\text {Iprop }}$ is approximately $0.3 \mathrm{~kJ} \mathrm{~m}^{-2}$ greater than $G_{\mathrm{Ic}}$; however, the variability is such that we see no distinct difference between composites formed from different veils.

Results for mode II fracture toughness are shown in Figure 9. The plot on the left of the figure shows mode II fracture toughness, $G_{\text {IIc }}$, plotted against the areal density of the veils; we observe a similar dependence on areal density as observed for mode I, though there is no strong dependence on linear density. The relationship between the mode II fracture toughnesses $G_{\text {IIprop }}$ and $G_{\text {IIc }}$ is shown on the right of Fig. 9. We observe that for veils of low areal density and low $G_{\text {IIc }}, G_{\text {IIprop }} \approx G_{\text {IIc }}$, though as fracture toughness increases, then $G_{\text {IIprop }}>G_{\text {IIc }}$; inspection of the date reveals that this occurs for areal densities above about $20 \mathrm{~g} \mathrm{~m}^{-2}$. We see almost no sensitivity of $G_{\text {IIc }}$ for any of the composites made from veils oriented in the CD. Note also that for areal densities around $15-20 \mathrm{~g} \mathrm{~m}^{-2}$, the values of $G_{\text {Ic }}$ and $G_{\text {IIc }}$ are similar to those reported by Kuwata and Hogg [16, 31, 43] at comparable areal densities. Recall also that network porosity and anisotropy were not dependent on areal density. We may be confident therefore 
that the observed dependence of $G_{\text {Ic }}$ and $G_{\text {IIc }}$ on areal density is attributable to no other aspect of veil structure.

Now, using Eqn. (4) with the data from Table 1, we may compute the expected number of fibres covering a point in the veils. Figures showing the mode I and mode II fracture toughnesses plotted against this parameter are provided in Figs. 10 \& 11 respectively; for clarity, data for composites formed from veils oriented in the CD are omitted. We observe that in each plot most of the data are well described by a single curve. This implies that the specific surface of the fibres, as given by Eqn. (2), and the mean pore size of the veils, as given by Eqn. (6), which both depend on fibre diameter, have negligible effect on the fracture toughnesses of the composites studied. Recall from Eqn. (5) that the fraction of the veil covered by no fibres depends only on the mean coverage. In the context of crack propagation, we can interpret this number as the expected fraction of the propagating crack tip that contains no fibres, i.e. the fraction of the interleave layer where epoxy passes from one side of the veil to the other. Mode I and mode II fracture toughnesses plotted against this parameter are provided in Figs. 12 \& 13 respectively; in these figures, the broken lines are for illustrative purposes only. We note however that the lower areal densities of the veils studied here are close to the minimum achievable with current manufacturing technologies. We state therefore that within the range permitted by existing veil technologies, the interlaminar fracture toughnesses, $G_{I c}$ and $G_{I I c}$ exhibit an approximately linear decrease with the fraction of the veil covered by no fibres. We will explore this apparent dependency further in subsequent work.

\section{Conclusions}

We have presented a systematic study of the influence of structural features of nonwoven fibre veils on the interlaminar fracture toughness of composites. Thorough analysis of the structure of the constituent veils showed that there was no effect of areal density on network porosity or 
anisotropy. Analysis of the composites revealed that whereas networks formed fibres with different linear density showed different mode I interlaminar fracture toughness at a given areal density, this difference was attributable entirely to their different coverage. For mode II the dependence of linear density was not apparent, however, there was greater variability in the data. Accordingly, both mode I and mode II fracture toughnesses exhibited no dependence on linear density when plotted against network coverage. We speculate that the mode I and mode II fracture toughnesses depend upon the fraction of the propagating crack tip that contains no fibres. This hypothesis is supported by our data and will be investigated further in subsequent studies. The behaviours of composites formed from a PEEK veils were consistent with those for PPS veils at the same areal density. Composites formed from the PEEK veil did exhibit a directional dependence of mode I and mode II fracture toughness which was not observed for the PPS veils, though we note that this veil exhibited high mechanical anisotropy.

\section{Acknowledgments}

Financial support from CONACyT, Mexico for the doctoral studies of V.A. Ramirez, is gratefully acknowledged as is the provision of veils by Technical Fibre Products Ltd., Cumbria, UK. Valuable discussions with colleagues at NCCEF, UK are acknowledged also.

\section{References}

[1] Ma P-C, Zhang Y. Perspectives of carbon nanotubes/polymer nanocomposites for wind blade materials. Renewable and Sustainable Energy Reviews. 2014;30(0):651-660.

[2] Airbus uses carbon/BMI composite. Reinforced Plastics. 1992;36(1):6-6.

[3] Boeing opts for composites for 7E7. Reinforced Plastics. 2003;47(7):10-10.

[4] Marsh G. Airbus A350 XWB update. Reinforced Plastics.54(6):20-24.

[5] Pora J. Advanced materials and technologies for A380 structure. Flight Airworthiness Support Technology, vol. 322003. p. 3-8.

[6] Ivens J, Albertsen H, Wevers M, Verpoest I, Peters P. Interlaminar fracture toughness of CFRP influenced by fibre surface treatment: Part 2. Modelling of the interface effect. Composites Science and Technology. 1995;54(2):147-159.

[7] Friedrich K, Walter R, Carlsson LA, Smiley AJ, Gillespie JW, Jr. Mechanisms for rate effects on interlaminar fracture toughness of carbon/epoxy and carbon/PEEK composites. Journal of Materials Science. 1989;24(9):33873398.

[8] Allegri G, Wisnom MR. A non-linear damage evolution model for mode II fatigue delamination onset and growth. International Journal of Fatigue. 2012;43(0):226-234. 
[9] Hojo M, Ando T, Tanaka M, Adachi T, Ochiai S, Endo Y. Modes I and II interlaminar fracture toughness and fatigue delamination of CF/epoxy laminates with self-same epoxy interleaf. International Journal of Fatigue. 2006;28(10):1154-1165.

[10] Jones R, Broughton W, Mousley RF, Potter RT. Compression failures of damaged graphite epoxy laminates. Composite Structures. 1985;3(2):167-186.

[11] Kim J-K, Sham M-L. Impact and delamination failure of woven-fabric composites. Composites Science and Technology. 2000;60(5):745-761.

[12] Chen F, Hodgkinson JM. Impact behaviour of composites with different fibre architecture. Proceedings of the Institution of Mechanical Engineers, Part G: Journal of Aerospace Engineering. 2009;223(7):1009-1017.

[13] Shyr T-W, Pan Y-H. Impact resistance and damage characteristics of composite laminates. Composite Structures. 2003;62(2):193-203.

[14] Baker AA, Jones R, Callinan RJ. Damage tolerance of graphite/epoxy composites. Composite Structures. 1985;4(1):15-44.

[15] Sanchez-Saez S, Barbero E, Zaera R, Navarro C. Compression after impact of thin composite laminates. Composites Science and Technology. 2005;65(13):1911-1919.

[16] Kuwata M. Mechanisms of Interlaminar Fracture Toughness using Non-Woven Veils as Interleaf Materials. Queen Mary, University of London, School of Engineering and Materials Science, Department of Materials, 2010.

[17] Iton Chou TI. Correlation of damage resistance under low velocity impact and Mode II delamination resistance in CFRP laminates Advanced Composite Materials. 1999;8(2):167-176.

[18] Choi NS KA, Williams JG. Delamination fracture of multidirectional carbon-fiber/epoxy composites under Mode I, Mode II and Mixed-Mode I/II loading. JOURNAL OF COMPOSITE MATERIALS. 1999;33(1):73-100.

[19] Chai H. The characterization of Mode I delamination failure in non-woven, multidirectional laminates. Composites. 1984;15(4):277-290.

[20] Garg AC. Delamination—a damage mode in composite structures. Engineering Fracture Mechanics. 1988;29(5):557-584.

[21] P.J. Hogg P. Strategies for Improving the Damage Tolerance of Future Composite Materials. RISO International Symposium on: Composite materials for structural performance: towards higher limits, RISO Technical University of Denmark2011. p. 509.

[22] ASTM. D 5528-1 Standard Test Method for Mode I Interlaminar Toughness of Unidirectional FiberReinforced Polymer Matrix Composites, 2001.

[23] BS I. BS 4415-2:1986, ISO 1924/2-1985 Determination of the tensile properties of paper and board Constant rate of elongation method, 1986.

[24] Walter TR, Subhash G, Sankar BV, Yen CF. Damage modes in 3D glass fiber epoxy woven composites under high rate of impact loading. Composites Part B: Engineering. 2009;40(6):584-589.

[25] Andersons J, König M. Dependence of fracture toughness of composite laminates on interface ply orientations and delamination growth direction. Composites Science and Technology. 2004;64(13-14):2139-2152.

[26] Kim K-Y, Curiskis JI, Ye L, Fu S-Y. Mode-I interlaminar fracture behaviour of weft-knitted fabric reinforced composites. Composites Part A: Applied Science and Manufacturing. 2005;36(7):954-964.

[27] Miyagawa H, Sato C, Ikegami K. Mode II interlaminar fracture toughness of multidirectional carbon fiber reinforced plastics cracking on 0//0 interface by Raman spectroscopy. Materials Science and Engineering: A. 2001;308(1-2):200-208.

[28] Hadavinia H, Ghasemnejad H. Effects of Mode-I and Mode-II interlaminar fracture toughness on the energy absorption of CFRP twill/weave composite box sections. Composite Structures. 2009;89(2):303-314.

[29] Mouritz AP, Baini C, Herszberg I. Mode I interlaminar fracture toughness properties of advanced textile fibreglass composites. Composites Part A: Applied Science and Manufacturing. 1999;30(7):859-870.

[30] Luo Y, Lv L, Sun B, Qiu Y, Gu B. Transverse impact behavior and energy absorption of three-dimensional orthogonal hybrid woven composites. Composite Structures. 2007;81(2):202-209.

[31] Kuwata M, Hogg PJ. Interlaminar toughness of interleaved CFRP using non-woven veils: Part 1. Mode-I testing. Composites Part A: Applied Science and Manufacturing. 2011;42(10):1551-1559.

[32] Cauchi-Savona S, Zhang C, Hogg P. Optimisation of crush energy absorption of non-crimp fabric laminates by through-thickness stitching. Composites Part A: Applied Science and Manufacturing. 2011;42(7):712-722. 
[33] Greenhalgh E, Hiley M. The assessment of novel materials and processes for the impact tolerant design of stiffened composite aerospace structures. Composites Part A: Applied Science and Manufacturing. 2003;34(2):151-161.

[34] Ishai O, Rosenthal H, Sela N, Drukker E. Effect of selective adhesive interleaving on interlaminar fracture toughness of graphite/epoxy composite laminates. Composites. 1988;19(1):49-54.

[35] Sela N, Ishai O. Interlaminar fracture toughness and toughening of laminated composite materials: a review. Composites. 1989;20(5):423-435.

[36] Gillespie Jr JW, Carlsson LA, Smiley AJ. Rate-dependent mode I interlaminar crack growth mechanisms in graphite/epoxy and graphite/PEEK. Composites Science and Technology. 1987;28(1):1-15.

[37] Smiley AJ, Pipes RB. Rate Effects on Mode I Interlaminar Fracture Toughness in Composite Materials. Journal of Composite Materials. 1987;21(7):670-687.

[38] Lee S-H, Noguchi H. Shear Characteristics of Hybrid Composites with Non-Woven Carbon Tissue. JSME International Journal Series A. 2001;44(4):535-541.

[39] Lee S-H, Noguchi H, Kim Y-B, Cheong S-K. Effect of Interleaved Non-Woven Carbon Tissue on Interlaminar Fracture Toughness of Laminated Composites: Part I - Mode II. Journal of Composite Materials. 2002;36(18):2153-2168.

[40] Lee S-H, Noguchi H, Kim Y-B, Cheong S-K. Effect of Interleaved Non-Woven Carbon Tissue on Interlaminar Fracture Toughness of Laminated Composites: Part II - Mode I. Journal of Composite Materials. 2002;36(18):2169-2181.

[41] ISO. Textiles Nonwoven Definition. 2011. p. 1.

[42] Albrech W. FH, Kittelmann W. Nonwoven Fabrics2003.

[43] Kuwata M, Hogg PJ. Interlaminar toughness of interleaved CFRP using non-woven veils: Part 2. Mode-II testing. Composites Part A: Applied Science and Manufacturing. 2011;42(10):1560-1570.

[44] Sampson WW. Modelling Stochastic Fibrous Materials with Mathematica®: Springer; 2008.

[45] Nakajima H. Nonwoven fabric for filter and filter for engine. Google Patents; 2006.

[46] Hutten IM. Handbook of nonwoven filter media: Elsevier; 2007.

[47] Eichhorn S, Sampson W. Relationships between specific surface area and pore size in electrospun polymer fibre networks. Journal of the Royal Society Interface. 2010;7(45):641-649.

[48] Sampson W, Urquhart S. The contribution of out-of-plane pore dimensions to the pore size distribution of paper and stochastic fibrous materials. J Porous Mater. 2008;15(4):411-417.

[49] HUNTSMAN. Hardener XB 3487. Warm-curing epoxy system based on Araldite LY 564 / Hardener XB 3486 / Hardener XB 3487: HUNTSMAN; 2013.

[50] I'Anson S, Sampson W. Competing Weibull and stress-transfer influences on the specific tensile strength of a bonded fibrous network. Composites Science and Technology. 2007;67(7):1650-1658.

[51] Fellers C, Andersson H, Hollmark H. The definition and measurement of thickness and density. Paper Structure and Properties. In: Bristow JA, Kolseth P ed, New York: Marcel Dekker; 1986.

[52] Mark JE. Polymer Data Handbook. Oxford University Press, Inc.; 1999.

[53] Arrese A, Mujika F. Influence of bending rotations on three and four-point bend end notched flexure tests. Engineering Fracture Mechanics. 2008;75(14):4234-4246.

\section{FIGURE CAPTIONS:}

Figure 1 Schematic of panel assembly. All dimensions in $\mathrm{mm}$.

Figure 2 Schematic of manufacture of mode I and II specimens including dimensions (mm) and layout details $\left(0_{8}^{U D 1}, 0^{U D 2}, \bar{V}\right)$.

Figure 3 Dependence of thickness on areal density for nonwovens formed from PPS fibres with different diameters.

Figure 4 Specific elastic modulus of veils plotted against areal density

Figure 5 Schematic of fixture for mode II testing; all dimensions in mm

Figure 6 Example data for mode I testing of composites made with 1 dtex PPS veils oriented in MD. Left: Load displacement curves; right: R-curves 
Figure 7 Example data for mode II testing of composites made with 1 dtex PPS veils oriented in MD. Left: Load displacement curves; right: R-curves

Figure 8 Mode I fracture toughness. Left: plotted against areal density; right: $G_{\text {Iprop }}$ plotted against $G_{\text {Ic }}$, broken line $1: 1$

Figure 9 Mode II fracture toughness. Left: plotted against areal density; right: $G_{\text {IIprop }}$ plotted against $G_{\text {IIc }}$, broken line $1: 1$

Figure 10 Mode I fracture toughness plotted against mean coverage (broken line illustrative only).

Figure 11 Mode II fracture toughness plotted against mean coverage (broken line illustrative only)

Figure 12 Mode I fracture toughness plotted against the probability of veil coverage zero

Figure 13 Mode II fracture toughness plotted against the probability of veil coverage zero 

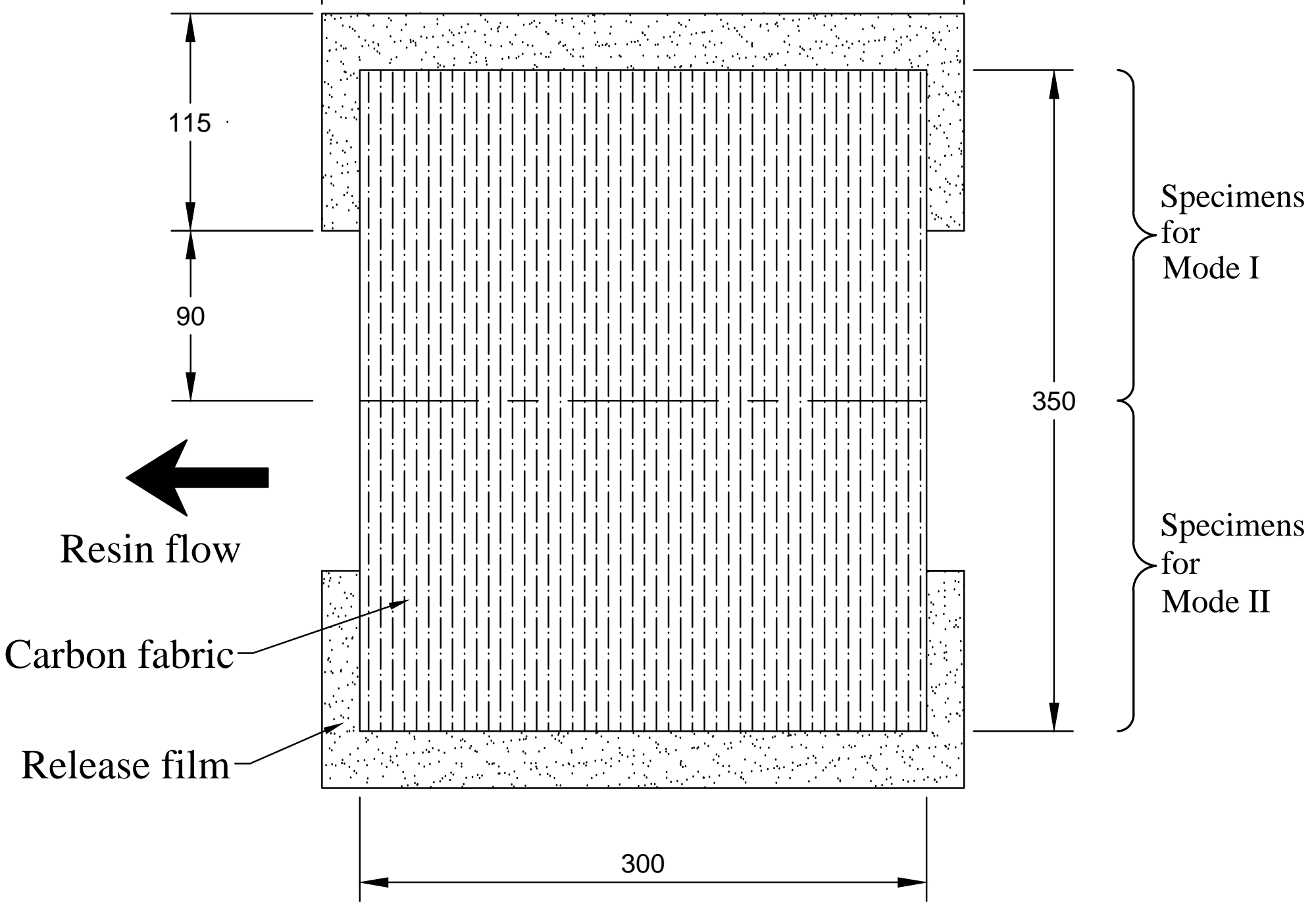

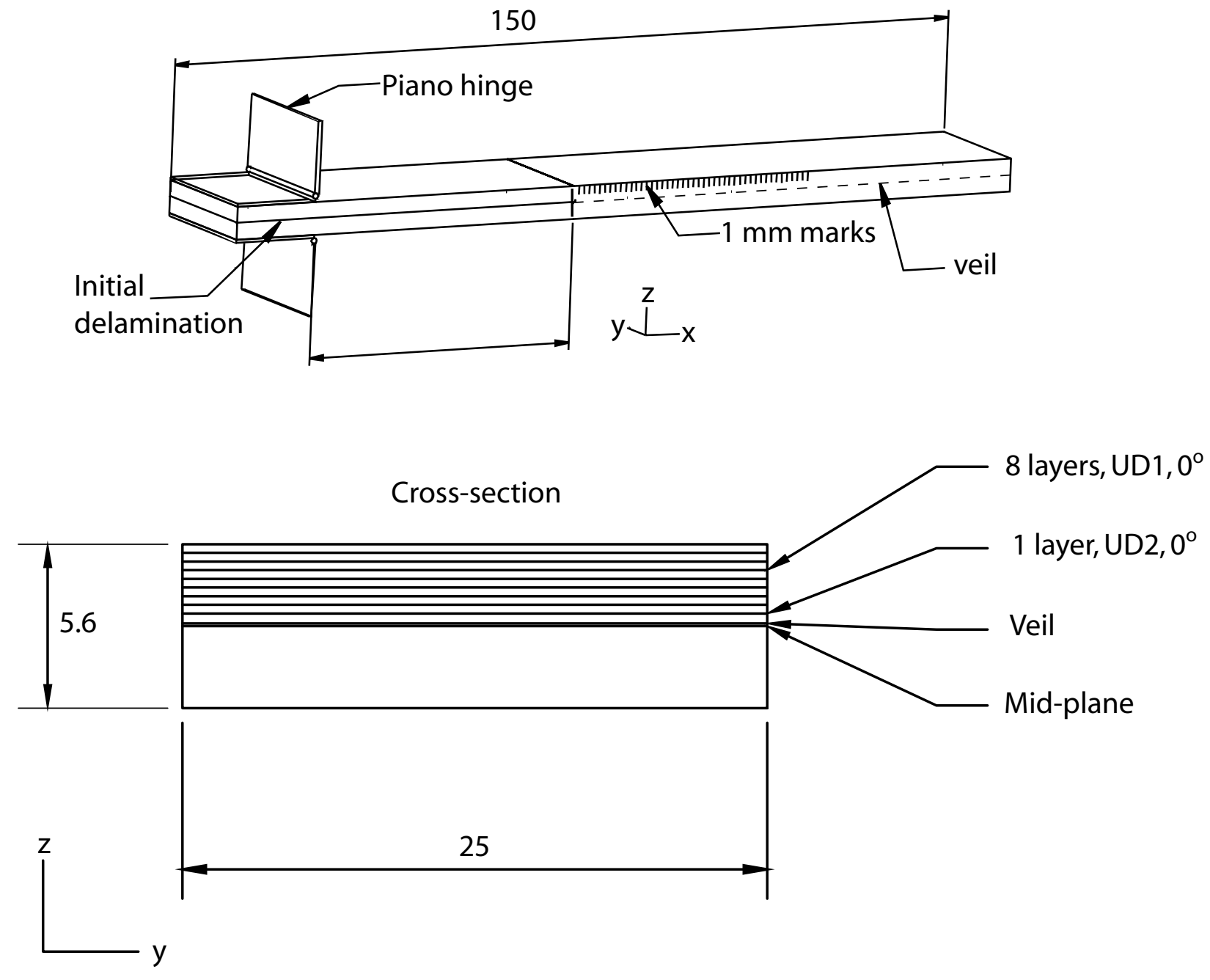


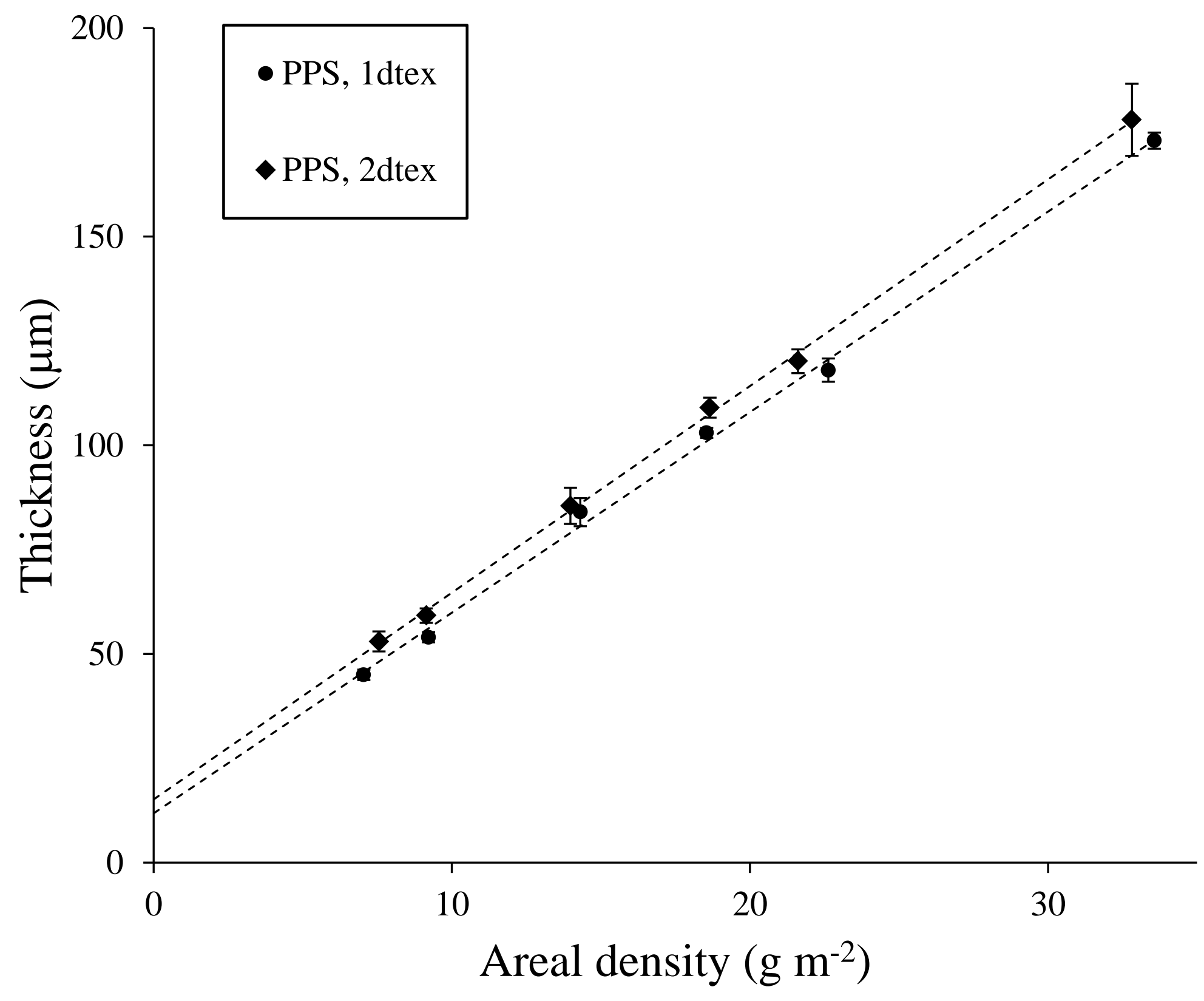




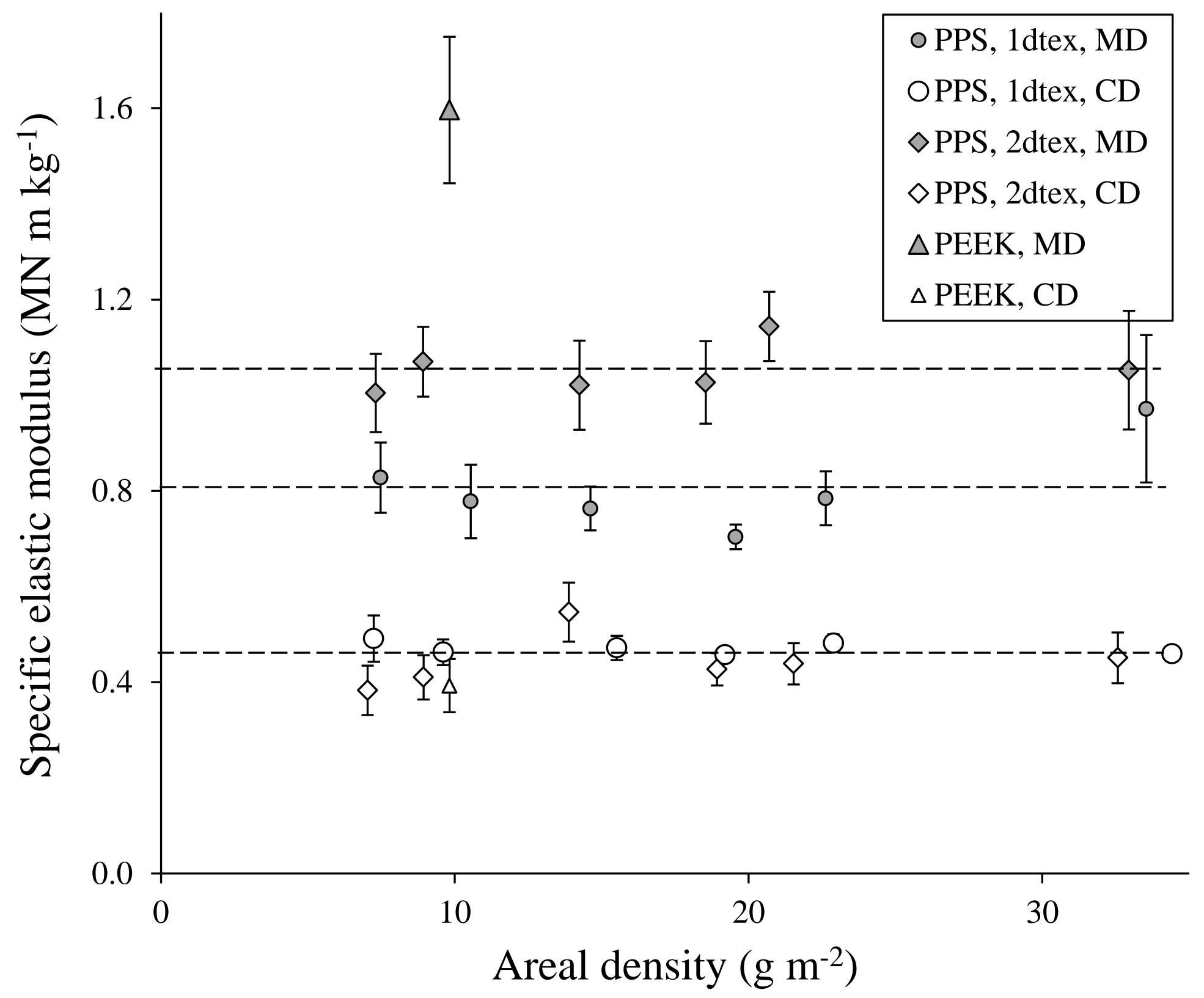




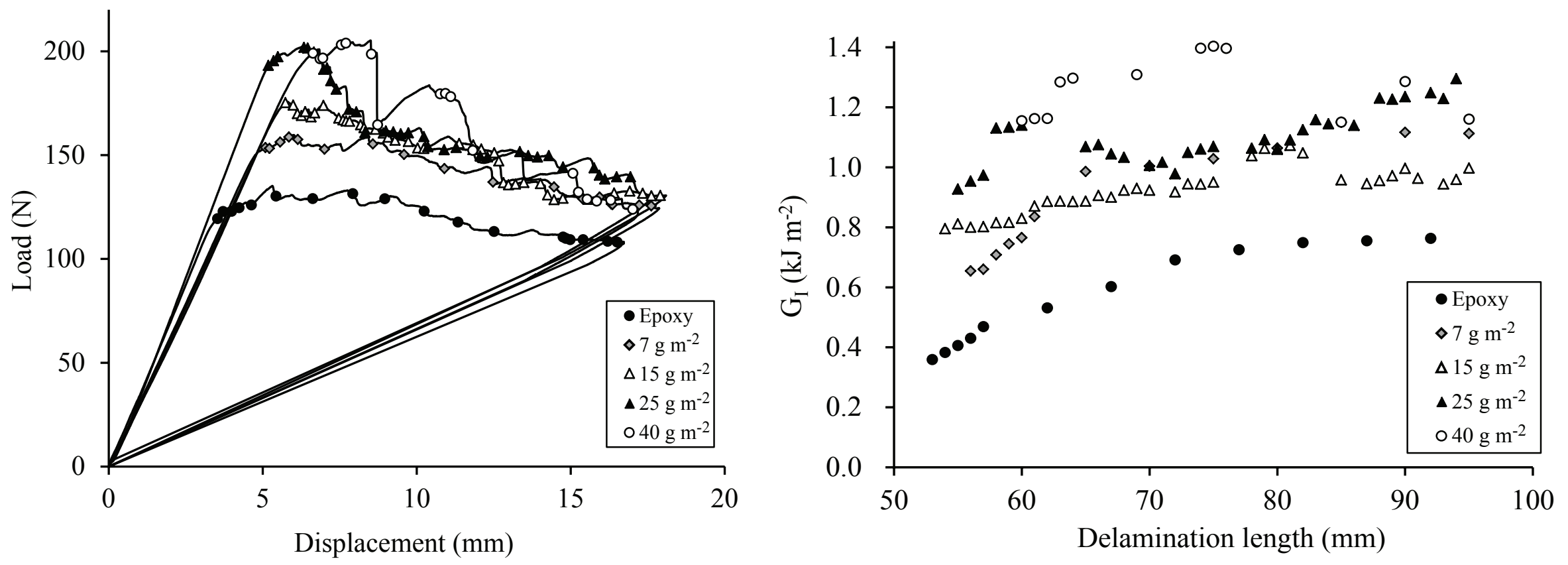

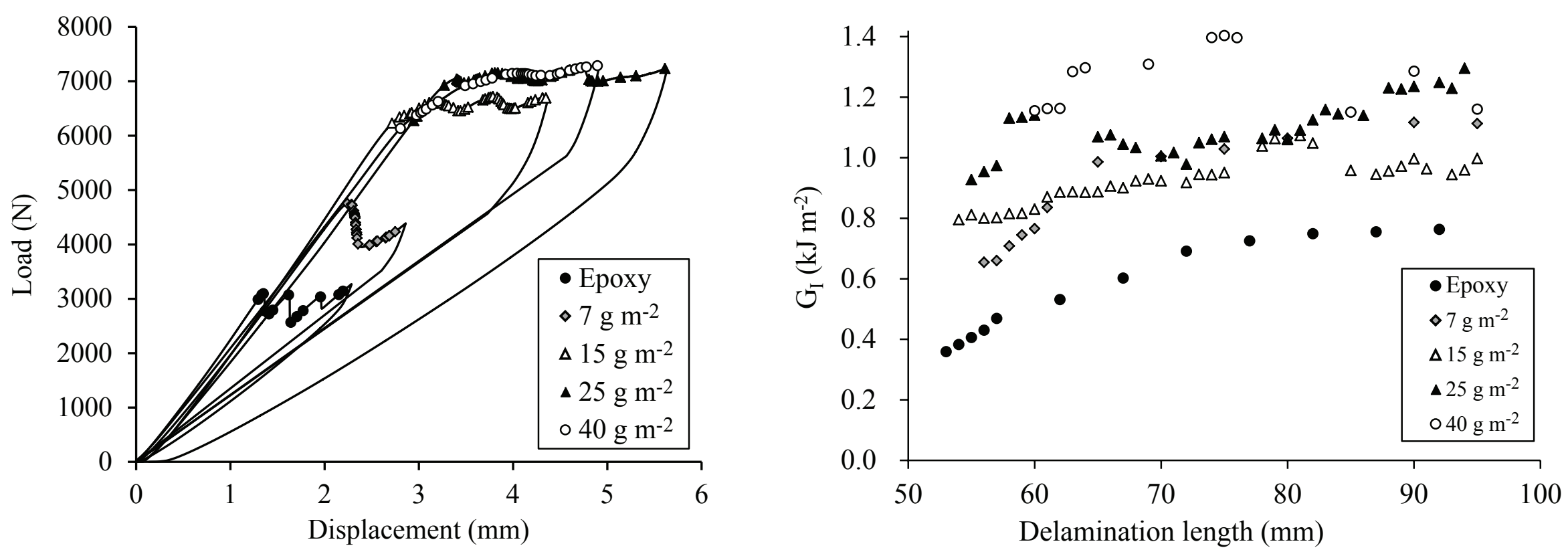

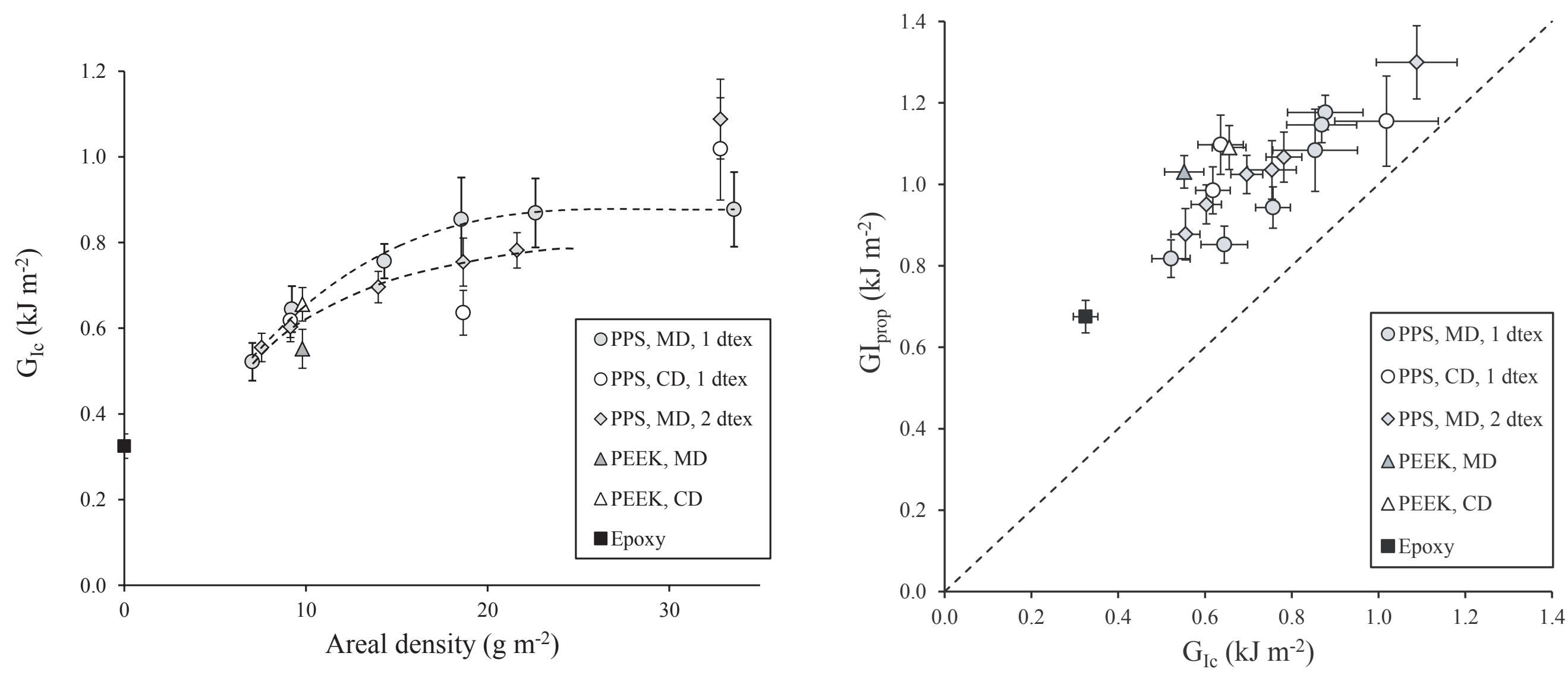

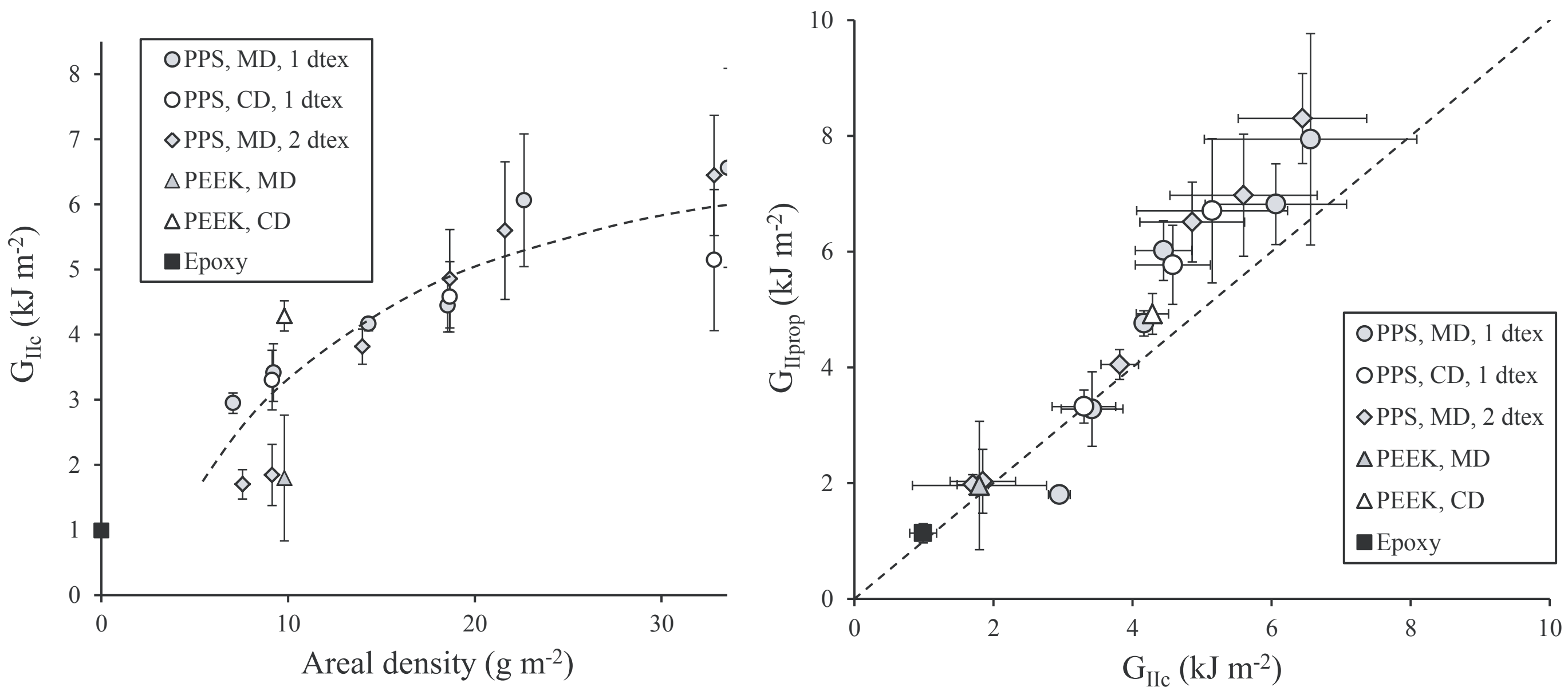


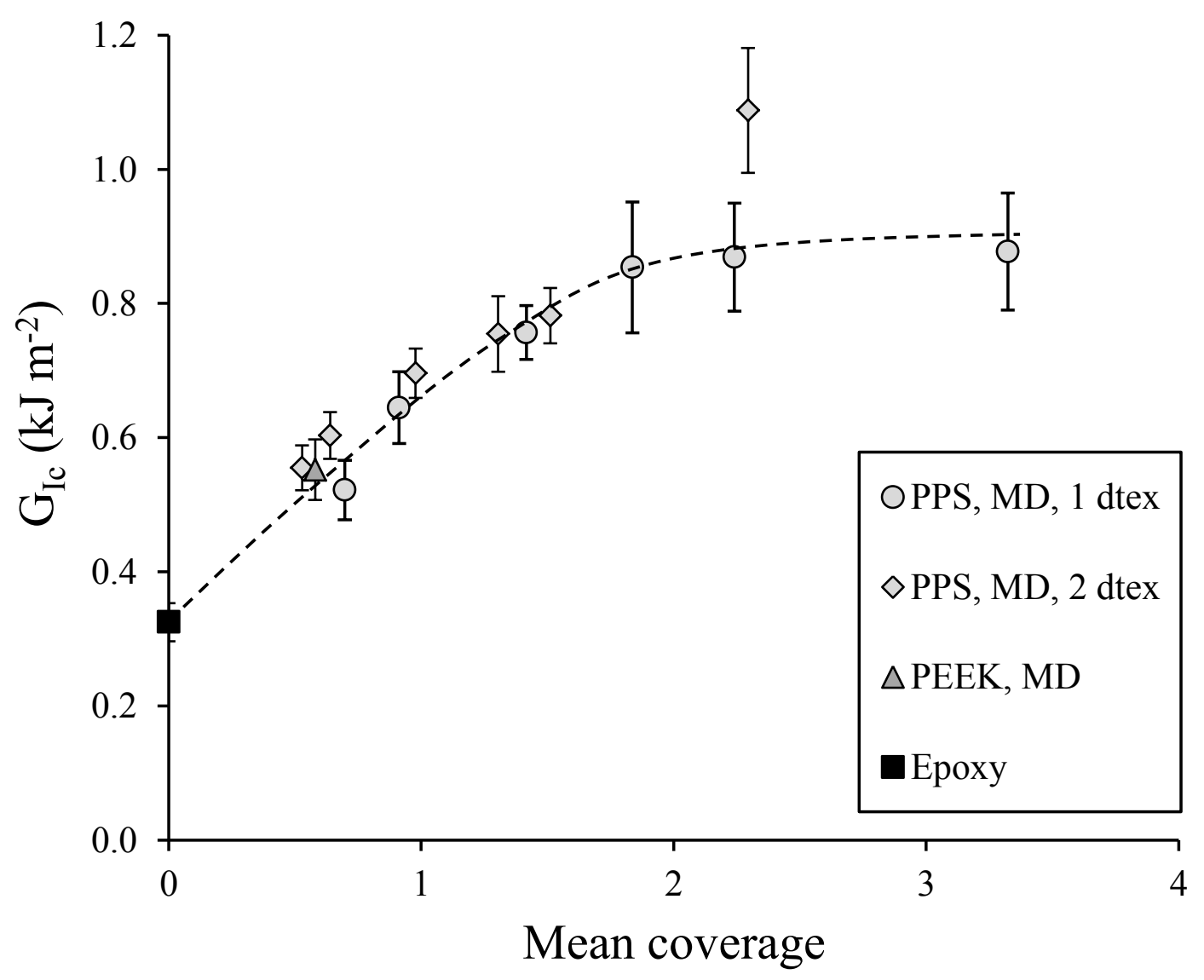




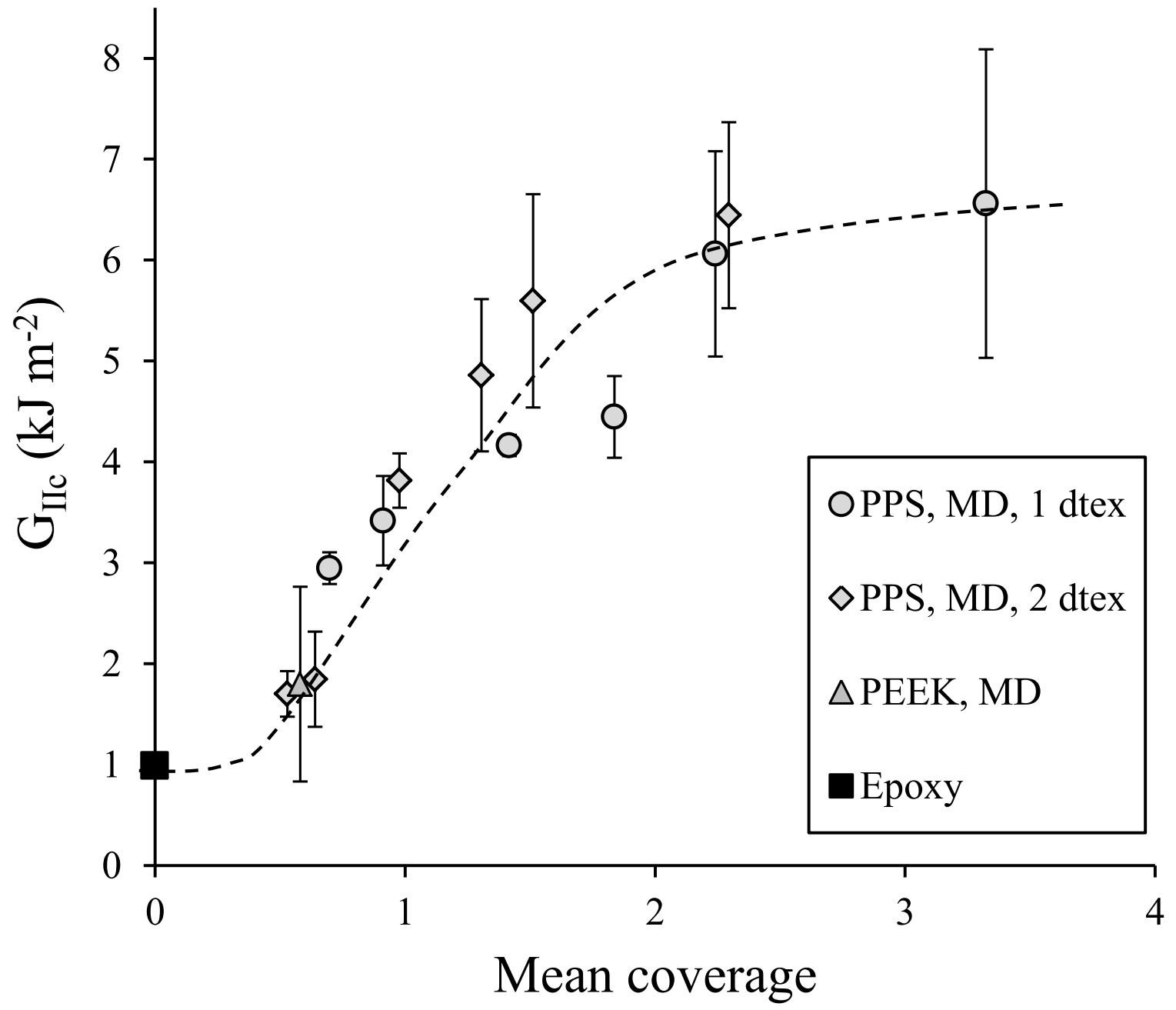




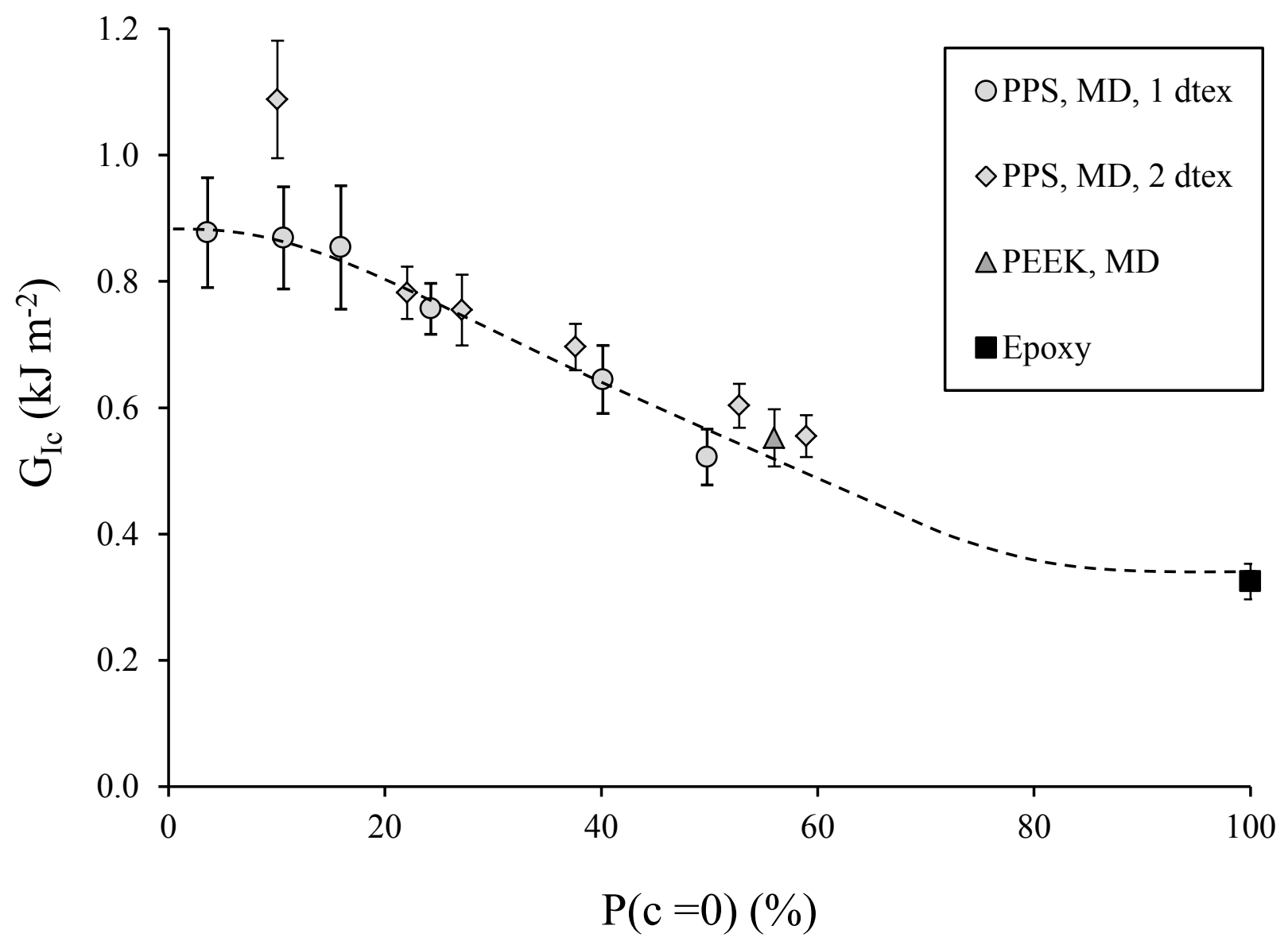




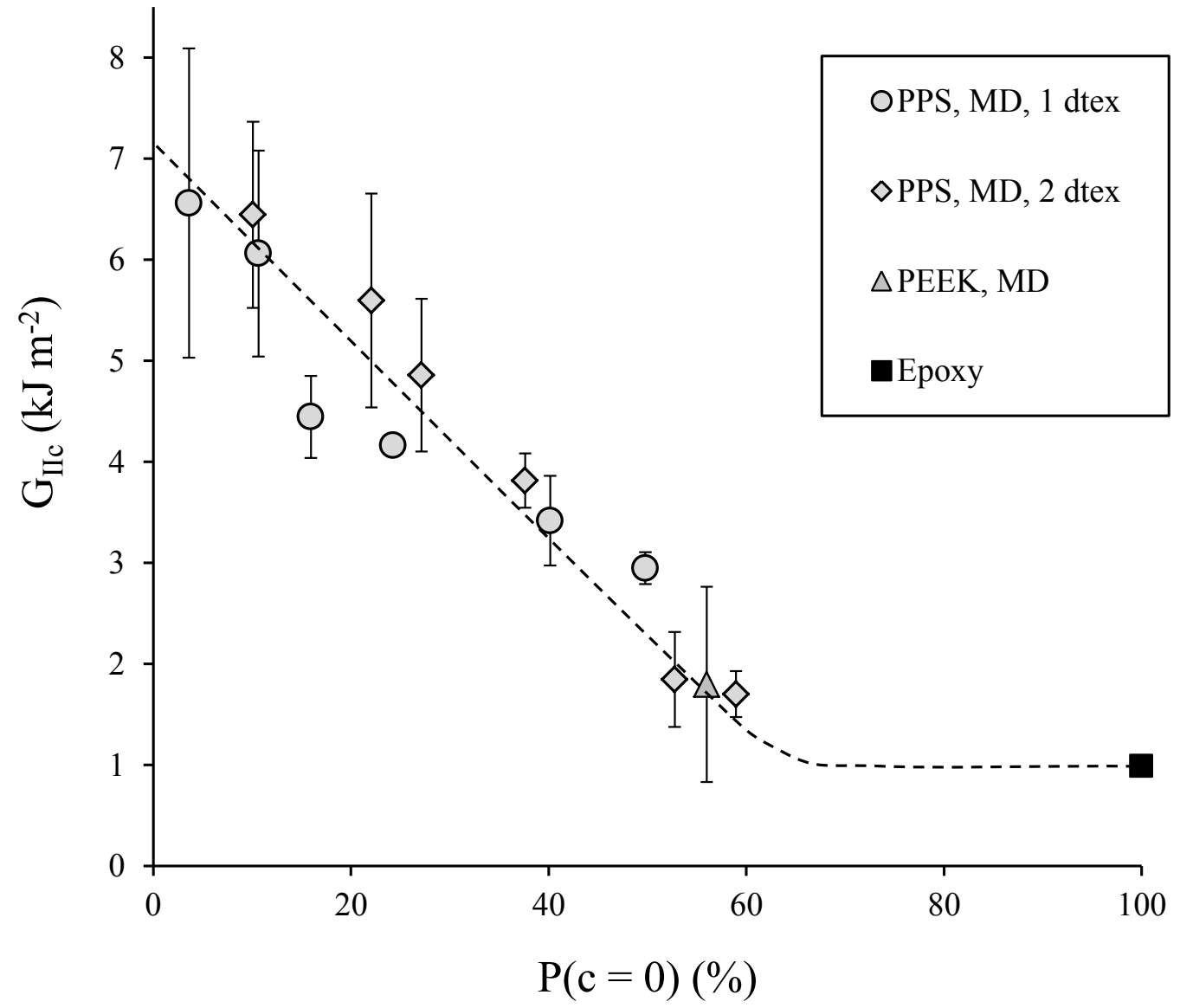

